\title{
Reference values and prediction equations for normal lung function in a non-smoking white urban population
}

\author{
C Michael Roberts, Kenneth D MacRae, Andrew J Winning, Lewis Adams, \\ W Anthony Seed
}

\begin{abstract}
Prediction equations for normal lung function have been derived from tests on 179 healthy, non-smoking, white urban dwellers. The subjects, 96 women (height 1.46-1.77 $\mathrm{m}$ ) and 83 men (height 1.61$1.96 \mathrm{~m}$ ) aged 18-86 years, underwent measurements of spirometric flow and volume, multi-breath helium dilution lung volumes, and single breath carbon monoxide transfer factor and the single breath nitrogen washout test. Regression analysis using height, age, and weight as independent variables was used to provide predicted values for both sexes. Correlation coefficients were similar to those found in previous studies but normal ranges for spirometic measurements were narrower than in many previous studies, and spirometric flow and volume measurements were higher than those obtained in studies that included cigarette smokers, reflecting our more stringent criteria for selecting subjects and the newer standardised technical methods adopted. Multibreath helium dilution values for total lung capacity were similar to those found in previous studies but the inspiratory vital capacity was larger and the residual volume reduced. Values for carbon monoxide transfer factor and the single breath nitrogen washout did not differ significantly from existing values. A complete set of lung function reference values and prediction equations for both sexes has been derived from a single population. The exclusion of cigarette smokers and subjects with respiratory symptoms has produced values that should have a greater sensitivity in the detection of mild lung disease.
\end{abstract}

Normal lung function values and ranges are conventionally calculated according to variables such as age, height, and weight, which contribute independently to predictions of lung function. The prediction equations should be derived from a normal and representative population tested by standardised technical methods and subjected to appropriate statistical analysis.

Many of the older studies still used as reference values fail to meet these criteria. The definition of normal subjects has varied widely and in some has included cigarette smokers and individuals with respiratory sym- ptoms, ${ }^{1-i}$ whereas in others no definition is given. ${ }^{89}$ Some studies have even discarded low values arbitrarily, using minimum spirometric values as selection criteria for normal subjects. ${ }^{110}$ Most recent studies have excluded smokers ${ }^{11-17}$ because the values found even in asymptomatic smokers may deviate from those in non-smokers.

Some published studies have used values for population subgroups defined by age, sex, race, or religion, ${ }^{78-21}$ or have produced normal ranges for a limited number of tests only. ${ }^{131416}$

As a result, many lung function laboratories have been forced to adopt reference values derived from several different lung function studies. In an attempt to overcome the lack of comprehensive data the European Community for Coal and Steel working party published compound prediction equations recommended for all people of European descent. ${ }^{22}$ These equations are based on data from studies carried out over 30 years, and thus incorporate the inconsistencies that arise from the use of variously defined normal groups. They also include data from smokers, and from studies that were not carried out according to currently recommended technical guidelines. ${ }^{22} 23$ They are not weighted for the numbers included in individual studies, and the normal ranges about the mean predicted values are "best estimates" with little statistical validity. Finally, the decline of lung function with age seen in longitudinal studies has differed significantly from the decline predicted from cross sectional data, ${ }^{24-27}$ suggesting that data from cross sectional studies reflect the population of that time and are valid only for a limited period before population changes render them obsolete. Until long term longitudinal studies are completed cross sectional data should be renewed at intervals. The present study was stimulated by a research requirement for contemporary normal ranges for some lung function values. The opportunity was taken to provide a comprehensive set of lung function prediction equations for both sexes, based on contemporary technical and statistical methods with rigorous selection procedures for normal subjects.

\section{Methods}

SUBJECTS

Subjects were defined as normal if they were lifelong non-smokers (not more than one cigarette a day for one year), had no history of respiratory or other serious illnesses, and gave negative replies to a simplified Medical 
Research Council respiratory health questionnaire, which covered current respiratory symptoms, previous medical history, time lost from work, and smoking history.

Subjects were mainly recruited through advertisements placed in the hospital foyer and fracture clinic; some elderly subjects were recruited as a result of advertisements placed in a pensioners' newsletter. Eighteen subjects were actively recruited from among hospital staff and medical students to provide a balance of the extremes of height. Of the 204 subjects who volunteered for the study, 25 were rejected because of a history of smoking (9), cough or dyspnoea mentioned on the questionnaire (8), concomitant non-respiratory disease (3), or failure to meet the volume reproducibility criteria of the lung function tests (5).

Each subject was measured for height by stadiometer (Harpenden) and weighed. Age, sex, and occupational details were recorded.

\section{APPARATUS}

Because of a laboratory upgrading, two separate systems were used for measurements of airflow, volumes, and transfer factor. Eighty six subjects were studied with the Gould lung function computer (model CPI 5000 IV) and 93 by a combination of the Morgan lung function transfer test (model $\mathrm{C}$ ) and the Hewlett Packard Vertek pneumotachograph (model 5000 VR). The comparability of these systems was studied with 15 normal subjects, who were tested on both systems on two different days. Intrasubject variability was evaluated in 15 subjects tested on the Gould unit on two occasions on separate days within one week at the same time of day. The nitrogen washout test used a combined Warren E Collins photo-optical nitrogen ionisation sensor (model 21232) and a Hewlett Packard Vertek pneumotachograph for all subjects.

Before the tests the required manoeuvres were demonstrated by the operator and subjects were encouraged and supervised throughout the performance of tests. All tests were carried out between 0900 and 1800 hours. Calibration checks on all instruments were carried out at least weekly.

\section{MEASUREMENTS}

Expiratory flow-volume curve

Expiratory flow-volume tracings were recorded from a computerised dry rolling sealed spirometer (Gould CPI) or pneumotachograph (Vertek) with real time plotting. Values from the first three tests performed with an acceptable technique and maximum effort (forced vital capacity (FVC) within $10 \%$ of the highest value) were recorded. The highest value for forced expiratory volume in onc second $\left(F E V_{1}\right), F V C$, peak expiratory flow (PEF), and flow at $50 \%$ of forced vital capacity $\left(\mathrm{FEF}_{50}\right)$ was taken independently from the three curves, back extrapolation being used to identify the starting point. ${ }^{28}$

Closed circuit multi-breath helium dilution Gould and Morgan units both use thermal conductivity cells to measure functional residual capacity (FRC), starting from $8 \%$ and $12 \%$ helium respectively (in $20.9 \%$ oxygen, the balance being nitrogen). Measurements were repeated on each subject with a 15 minute interval until two FRC determinations were within $200 \mathrm{ml}$ of each other; usually two and occasionally three attempts were required. During the rebreathing period two inspiratory vital capacity (IVC) manoeuvres were performed. Tidal volume breathing was recorded throughout the test, which continued for at least seven minutes, and until the helium concentration had remained stable for at least 60 seconds. The residual volume (RV) was derived from the FRC minus expiratory reserve volume and total lung capacity (TLC) from RV plus the higher IVC value. The mean of the results from the two tests was taken.

\section{Carbon monoxide transfer capacity}

Carbon monoxide transfer factor (TLCO) was measured by the single breath method ${ }^{29}$ on both Gould and Morgan systems with a 10 second breath holding time. Carbon monoxide was measured by electrochemical (Gould) or infrared absorption (Morgan) cells with an initial concentration of $0.3 \%$ in $20.9 \%$ oxygen and $10-14 \%$ helium, the balance being nitrogen.

At least two attempts were made and accepted if the IVC fell within $10 \%$ of the IVC obtained during the multi-breath helium dilution study. The TLco from the first two acceptable tests was taken. Alveolar volume was measured simultaneously from the dilution of $10 \%$ (Gould) or $14 \%$ (Morgan) helium and was used to calculate the transfer factor corrected for volume ( $\mathrm{TLCO}_{\mathrm{L}} / \mathrm{VA}$ ). The mean of two acceptable tests was taken for the TLCO and Tlco/Va.

\section{Single breath nitrogen washout}

This was performed as described by Buist and Ross $^{30}$ after the other tests. Expiratory flow was displayed on an oscilloscope trace to provide visual feedback to assist the subject to maintain flow rates below $0.51 / \mathrm{s}$. An IVC within $10 \%$ of the IVC recorded during the multi-breath helium dilution test was required for a test to be accepted. Values from two tests meeting these criteria were recorded; closing volume (CV), closing capacity (CC), and slope of phase III were determined from each, mean values being recorded.

Table 1 Age distribution of normal subjects subdivided by sex

\begin{tabular}{lll}
\hline \multicolumn{3}{l}{ Number $(\%)$ of } \\
\cline { 2 - 4 } Age $(y)$ & men & women \\
\hline $18-29$ & $21(25)$ & $29(30)$ \\
$30-39$ & $16(19)$ & $11(11)$ \\
$40-49$ & $12(14)$ & $17(18)$ \\
$50-59$ & $14(17)$ & $11(11)$ \\
$60-69$ & $11(13)$ & $17(18)$ \\
$>70$ & $9(11)$ & $11(11)$ \\
Total & $83(100)$ & $96(100)$ \\
Mean & $44 \cdot 9$ & $44 \cdot 6$ \\
SD & $17 \cdot 4$ & $18 \cdot 5$ \\
Skew & $0 \cdot 35$ & $0 \cdot 30$ \\
\hline
\end{tabular}


Table 2 Range, mean, SD, skew, and kurtosis of lung function variables for men and women

\begin{tabular}{|c|c|c|c|c|c|}
\hline Variable & Range & Mean & $S D$ & Skew & Kurtosis \\
\hline \multicolumn{6}{|l|}{ MEN } \\
\hline $\mathrm{FEV}_{1}(\mathbf{l})$ & $2 \cdot 20-5 \cdot 87$ & 3.98 & 0.90 & $0 \cdot 11$ & -0.54 \\
\hline FVC (1) & $2.93-8.02$ & $5 \cdot 12$ & 1.05 & $0 \cdot 37$ & 0.08 \\
\hline TLC (1) & $4 \cdot 83-9 \cdot 72$ & $7 \cdot 10$ & 1.04 & $0 \cdot 11$ & -0.37 \\
\hline IVC (1) & $3 \cdot 40-7 \cdot 90$ & $5 \cdot 25$ & 0.94 & 0.46 & 0.34 \\
\hline FRC (1) & $1 \cdot 99-5 \cdot 17$ & $3 \cdot 51$ & 0.82 & $0 \cdot 24$ & $-0 \cdot 78$ \\
\hline RV (1) & $0.87-3.55$ & 1.90 & 0.54 & 0.81 & $0 \cdot 85$ \\
\hline $\operatorname{PEF}(1 / s)$ & $4 \cdot 41-13 \cdot 85$ & $10 \cdot 59$ & $1 \cdot 77$ & -0.74 & $1 \cdot 00$ \\
\hline $\mathrm{FEF}_{50}(\mathrm{l} / \mathrm{s})$ & $1 \cdot 76-8 \cdot 15$ & $4 \cdot 54$ & 1.58 & 0.41 & -0.32 \\
\hline $\mathrm{TLCO}(\mathrm{mmol} / \mathrm{min} / \mathrm{kPa})$ & $5 \cdot 18-16 \cdot 54$ & $10 \cdot 84$ & $2 \cdot 52$ & 0.53 & $1 \cdot 21$ \\
\hline $\mathrm{TLCO}_{\mathrm{LA}} \mathrm{V}(\mathrm{mmol} / \mathrm{min} / \mathrm{kPa} / \mathrm{l})$ & $1 \cdot 03-2 \cdot 37$ & $1 \cdot 71$ & 0.32 & $0 \cdot 74$ & $1 \cdot 15$ \\
\hline$\Delta \mathrm{N}_{2} \%(\% / 1)$ & $0.35-2.90$ & $0 \cdot 84$ & 0.49 & $1 \cdot 88$ & $4 \cdot 50$ \\
\hline CV\% & $3 \cdot 70-16 \cdot 54$ & $10 \cdot 73$ & $2 \cdot 72$ & $-0 \cdot 46$ & $0 \cdot 74$ \\
\hline $\mathrm{CC} \%$ & $19 \cdot 15-64 \cdot 42$ & $36 \cdot 69$ & $9 \cdot 47$ & $1 \cdot 34$ & $2 \cdot 04$ \\
\hline \multicolumn{6}{|l|}{ WOMEN } \\
\hline $\mathrm{FEV}_{1}(\mathrm{l})$ & $1 \cdot 46-4 \cdot 61$ & 2.96 & 0.69 & -0.07 & -0.71 \\
\hline FVC (1) & $1 \cdot 73-5 \cdot 53$ & $3 \cdot 67$ & 0.77 & $0 \cdot 14$ & $-0 \cdot 25$ \\
\hline TLC (l) & $3 \cdot 36-7 \cdot 27$ & $5 \cdot 24$ & $0 \cdot 70$ & $0 \cdot 23$ & $0 \cdot 29$ \\
\hline IVC (1) & $1.49-5.57$ & $3 \cdot 69$ & 0.75 & -0.01 & $0 \cdot 21$ \\
\hline FRC (1) & $1.59-3.73$ & $2 \cdot 67$ & 0.48 & $0 \cdot 10$ & $-0 \cdot 27$ \\
\hline RV (1) & $0 \cdot 72-2 \cdot 54$ & $1 \cdot 55$ & $0 \cdot 40$ & 0.65 & -0.04 \\
\hline $\operatorname{PEF}(1 / s)$ & $3 \cdot 32-10 \cdot 55$ & $7 \cdot 41$ & 1.52 & -0.35 & 0.07 \\
\hline $\mathrm{FEF}_{50}(1 / \mathrm{s})$ & $1.30-6 \cdot 66$ & $3 \cdot 86$ & $1 \cdot 26$ & $0 \cdot 12$ & $-0 \cdot 60$ \\
\hline $\mathrm{TLCO}(\mathrm{mmol} / \mathrm{min} / \mathrm{kPa})$ & $5.03-13.93$ & $7 \cdot 96$ & 1.53 & -0.46 & $0 \cdot 74$ \\
\hline $\mathrm{TLCo} / \mathrm{VA}(\mathrm{mmol} / \mathrm{min} / \mathrm{kPa} / \mathrm{l})$ & $1 \cdot 11-2 \cdot 75$ & 1.69 & $0 \cdot 29$ & $-0 \cdot 77$ & $1 \cdot 83$ \\
\hline$\Delta \mathrm{N}_{2} \%(\% / 1)$ & $0.05-4.50$ & $1 \cdot 09$ & 0.73 & $2 \cdot 17$ & $6 \cdot 83$ \\
\hline $\mathrm{CV} \%$ & $2 \cdot 25-28 \cdot 90$ & $13 \cdot 25$ & $6 \cdot 59$ & $0 \cdot 34$ & -0.65 \\
\hline $\mathrm{CC} \%$ & $18 \cdot 00-57 \cdot 59$ & $38 \cdot 27$ & $9 \cdot 37$ & $0 \cdot 26$ & -0.65 \\
\hline
\end{tabular}

$\mathrm{FEV}_{1}$-forced expiratory volume in one second; FVC-forced vital capacity; TLC-total lung capacity; IVC-inspiratory vita capacity; FRC-functional residual capacity; RV-residual volume; $\mathrm{PEF}$-peak expiratory flow; $\mathrm{FEF}_{50}$-forced expiratory flow at $50 \%$ of forced vital capacity; TLCO-carbon monoxide transfer factor; VA-alveolar volume; $\mathrm{N}_{2}-$ nitrogen; $\mathrm{CV}-$ closing volume; $\mathrm{CC}-$ closing capacity.

Closing volume was taken as the point of terminal increase of nitrogen concentration along the alveolar plateau and was expressed as a proportion of the vital capacity $(\mathrm{CV} / \mathrm{VC} \%)$. In cases where no clear point of terminal increase in nitrogen concentration (phase IV) could be identified closing volume was recorded as $0 \%$. Closing capacity (closing volume plus residual volume from the multi-breath helium dilution) was expressed as a proportion of TLC. The slope of phase III was measured as the percentage increase in nitrogen concentration per litre of expired gas after the first $750 \mathrm{ml}$ had been discarded $\left(\Delta \mathrm{N}_{2} \% / 1\right)$. The

Table 3 Regression coefficients and constants for prediction equations

\begin{tabular}{|c|c|c|c|c|c|c|}
\hline \multirow[b]{2}{*}{ Variable } & \multicolumn{6}{|c|}{ Coefficient term } \\
\hline & Height (m) & Age (y) & Weight (kg) & Constant & $S D$ & $R^{2}$ \\
\hline \multicolumn{7}{|l|}{ MEN } \\
\hline $\mathrm{FEV}_{1}(\mathrm{l})$ & 3.961 & -0.033 & - & $-1 \cdot 558$ & 0.51 & 0.68 \\
\hline FVC (1) & 6.628 & -0.028 & - & $-5 \cdot 377$ & 0.64 & 0.63 \\
\hline FEV/FVC\% & $-21 \cdot 476$ & -0.242 & - & $126 \cdot 252$ & $6 \cdot 88$ & 0.25 \\
\hline $\operatorname{PEF}(1 / s)$ & $5 \cdot 317$ & -0.062 & - & 3.884 & $1 \cdot 24$ & 0.52 \\
\hline $\mathrm{FEF}_{50}(1 / \mathrm{s})$ & - & -0.044 & - & 6.456 & 1.41 & 0.22 \\
\hline $\operatorname{TLC}(1)$ & $7 \cdot 956$ & - & - & -6.948 & 0.77 & 0.48 \\
\hline IVC (1) & $6 \cdot 791$ & -0.021 & - & $-5 \cdot 824$ & 0.58 & 0.63 \\
\hline FRC (1) & $7 \cdot 502$ & 0.009 & -0.033 & $-7 \cdot 608$ & 0.68 & 0.33 \\
\hline $\mathrm{RV}(1)$ & $3 \cdot 380$ & 0.020 & -0.014 & -3.927 & 0.43 & 0.37 \\
\hline RV/TLC\% & - & $0 \cdot 246$ & - & $16 \cdot 108$ & $4 \cdot 58$ & 0.50 \\
\hline TLCO & $14 \cdot 005$ & -0.074 & - & $-10 \cdot 803$ & $1 \cdot 89$ & 0.52 \\
\hline TLCo/VA & - & -0.009 & - & 2.086 & 0.34 & $0 \cdot 18$ \\
\hline$\angle N_{2}(\% 1)$ & - & 0.015 & - & $0 \cdot 207$ & 0.42 & $0 \cdot 29$ \\
\hline $\mathrm{CV}(\%)$ & - & $0 \cdot 250$ & - & $3 \cdot 362$ & $5 \cdot 02$ & 0.50 \\
\hline $\mathrm{CC}(\%)$ & - & 0.387 & - & $20 \cdot 488$ & $5 \cdot 59$ & 0.66 \\
\hline \multicolumn{7}{|l|}{ WOMEN } \\
\hline $\mathrm{FEV}_{1}(\mathrm{l})$ & $3 \cdot 321$ & -0.025 & - & -1.394 & 0.39 & 0.67 \\
\hline FVC (1) & $4 \cdot 321$ & -0.023 & - & $-2 \cdot 379$ & 0.49 & 0.60 \\
\hline FEV/FVC\% & - & -0.172 & - & $88 \cdot 134$ & $6 \cdot 74$ & $0 \cdot 18$ \\
\hline $\operatorname{PEF}(1 / s)$ & $4 \cdot 087$ & -0.050 & - & 2.945 & $1 \cdot 10$ & 0.49 \\
\hline $\operatorname{FEF}_{51}(1 / \mathrm{s})$ & - & -0.038 & - & $5 \cdot 556$ & 1.05 & 0.31 \\
\hline $\operatorname{TLC}(1)$ & $7 \cdot 107$ & - & - & -6.435 & 0.53 & 0.43 \\
\hline IVC (1) & 4.025 & -0.022 & - & -1.943 & 0.51 & 0.55 \\
\hline FRC (1) & $5 \cdot 867$ & 0.009 & -0.022 & -5.972 & 0.35 & 0.48 \\
\hline RV (1) & $2 \cdot 548$ & 0.017 & - & $-3 \cdot 387$ & 0.29 & 0.49 \\
\hline RV TLC\% & - & 0.346 & - & $14 \cdot 265$ & $5 \cdot 52$ & 0.57 \\
\hline TLCO & $7 \cdot 391$ & -0.037 & - & $-2 \cdot 516$ & $1 \cdot 19$ & 0.41 \\
\hline TLCO VA & - & -0.006 & - & 1.937 & $0 \cdot 27$ & $0 \cdot 12$ \\
\hline$-\mathrm{N}_{2}(\% \mathrm{l})$ & - & 0.008 & - & 0.753 & 0.72 & 0.04 \\
\hline $\mathrm{CV}(\%)$ & - & $0 \cdot 248$ & - & 2.599 & $4 \cdot 83$ & 0.47 \\
\hline $\mathrm{CC}(1 / 1)$ & - & 0.420 & - & $19 \cdot 713$ & $5 \cdot 55$ & 0.65 \\
\hline
\end{tabular}

For abbreviations sec table 2 . 

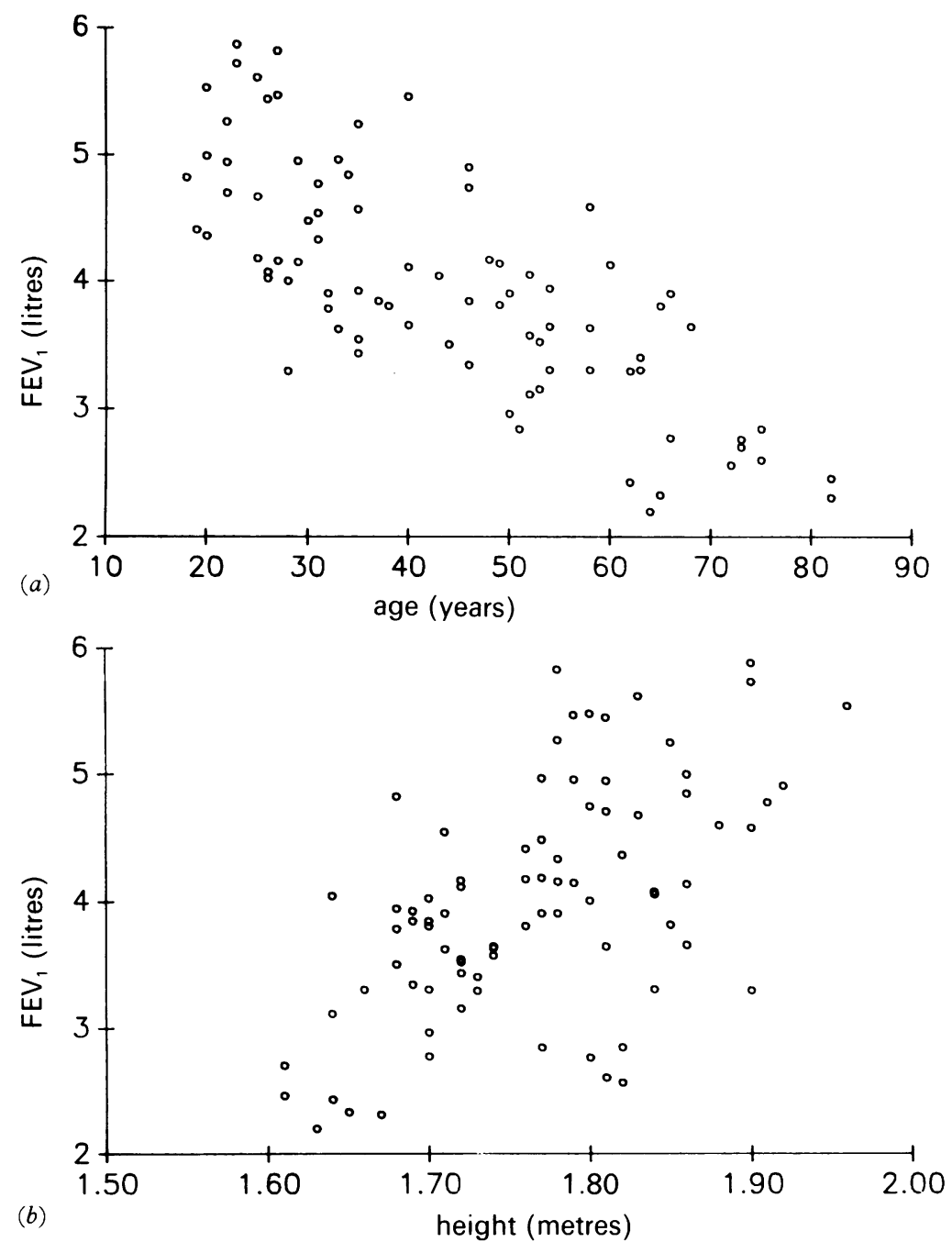

Figure 1 Scattergram of measured forced expiratory volume in one second (FEV $)$ against ( $a$ ) age and (b) height in the 83 male subjects. The equations, derived by linear regression, are: (a) $F E V_{1}=-0.04$ age $+5.73(r=-076) ;$ (b) $F E V_{1}=6.59$ height $-7.65(r=0.58)$.

measurement was made from a visually determined "best fit" line drawn through the remaining alveolar phase by one observer.

ANALYSIS

All data were transferred to the University of London computer (Amdahl 5890) and analysed with the Statistical Package for Social Sciences (SPSS Inc, Chicago). Transcription error checks were carried out at each stage of data input. Scatterplots of lung function variables against height, weight, and age were examined initially for each sex, and outlying values investigated for transcription or methodological error. The distribution of these independently contributing variables was examined for skew and kurtosis to determine whether transformations were necessary before regression analysis could be performed.

Table 4 Alternative expressions for spirometric results in men over 25 years

\begin{tabular}{llllll}
\hline Variable & $\begin{array}{l}\text { Height } \\
(m)\end{array}$ & $\begin{array}{l}\text { Age } \\
(y)\end{array}$ & Constant & $S D$ & $R^{2}$ \\
\hline FEV $_{1}(1)$ & 3.768 & -0.033 & -1.252 & 0.51 & 0.69 \\
FVC $(1)$ & 5.816 & -0.028 & -3.931 & 0.64 & 0.63 \\
PEF $(1 / \mathrm{s})$ & 5.699 & -0.063 & 3.309 & 1.24 & 0.52 \\
FEV $/$ FVC (\%) & - & -0.207 & 86.855 & 7.02 & 0.21 \\
\hline
\end{tabular}

For abbreviations see table 2 .
Multiregression analysis by forward, backward, and stepwise methods was used to produce prediction equations for each lung function variable with the independent variables and a constant. Predicted values were then plotted against the original values to produce correlation coefficients, coefficients squared, and standard deviations from the predicted means. The criterion of significance for including a variable in the regression equation was $p<0.05$. The linearity of decline of spirometric variables with age was tested by comparing the correlation of regression equations derived for age subsets and for the whole group. Plots of residual values against predicted values were made. When indicated, square root, squared, and log transformations were tested for better fits with the regression line.

\section{Results}

The variability between measurements made on the two lung function machines and on the Gould machine on two occasions are given in appendix tables $\mathrm{A}$ and $\mathrm{B}$. The differences between the mean values obtained on the two systems were small and in general similar to the difference between repeat measurements on the Gould system. Data obtained with the two systems were therefore combined for the remainder of the calculations.

Of the 179 subjects who completed the spirometric, helium dilution, and gas transfer measurements, 96 were women (mean height 1.64 (range 1.46-1.77) $\mathrm{m}$, mean weight 63.9 (range $42-98) \mathrm{kg}$ ) and 83 were men (mean height 1.77 (range 1.61-1.96) $\mathrm{m}$, mean weight $75 \cdot 2$ (range $52 \cdot 8-108 \cdot 4$ ) $\mathrm{kg}$ ). A positive skew towards higher weight was seen in the female group but other variables had a normal distribution. The age distribution is detailed in table 1. Eighteen subjects were unable to complete the single breath nitrogen washout test satisfactorily, and in a further 17 phase IV could not be identified. Thus satisfactory data for this test were obtained from 144 subjects ( 76 women and 68 men). Mean values, with the range and standard deviation with skew and kurtosis values for each lung function variable, are shown in table 2 . The regression coefficients and constants for the prediction equations of lung function are described in table 3 . Figure 1 gives an example showing how $\mathrm{FEV}_{1}$ varied with height and age.

The linearity of decline of spirometric variables with age, as assessed by correlation coefficients and residuals, did not improve when ages of 25 or 30 rather than 18 years were taken as the starting points. Prediction equations derived from this group of subjects appear therefore to be valid from age 18 . Other studies have suggested that decline in spirometric lung function in men does not begin until the age of 25 or more ${ }^{24-27}$; we have therefore included regression equations for men from 25 years upwards (table 4).

Squared, square root, and log transformations were explored to improve the fit and reduce the scatter for the slope of the phase III of the nitrogen washout, which has a heteroscedastic distribution (fig 2). The best fit log transformation reduced the coefficient of skew from 1.526 untransformed to 0.032 but failed to 

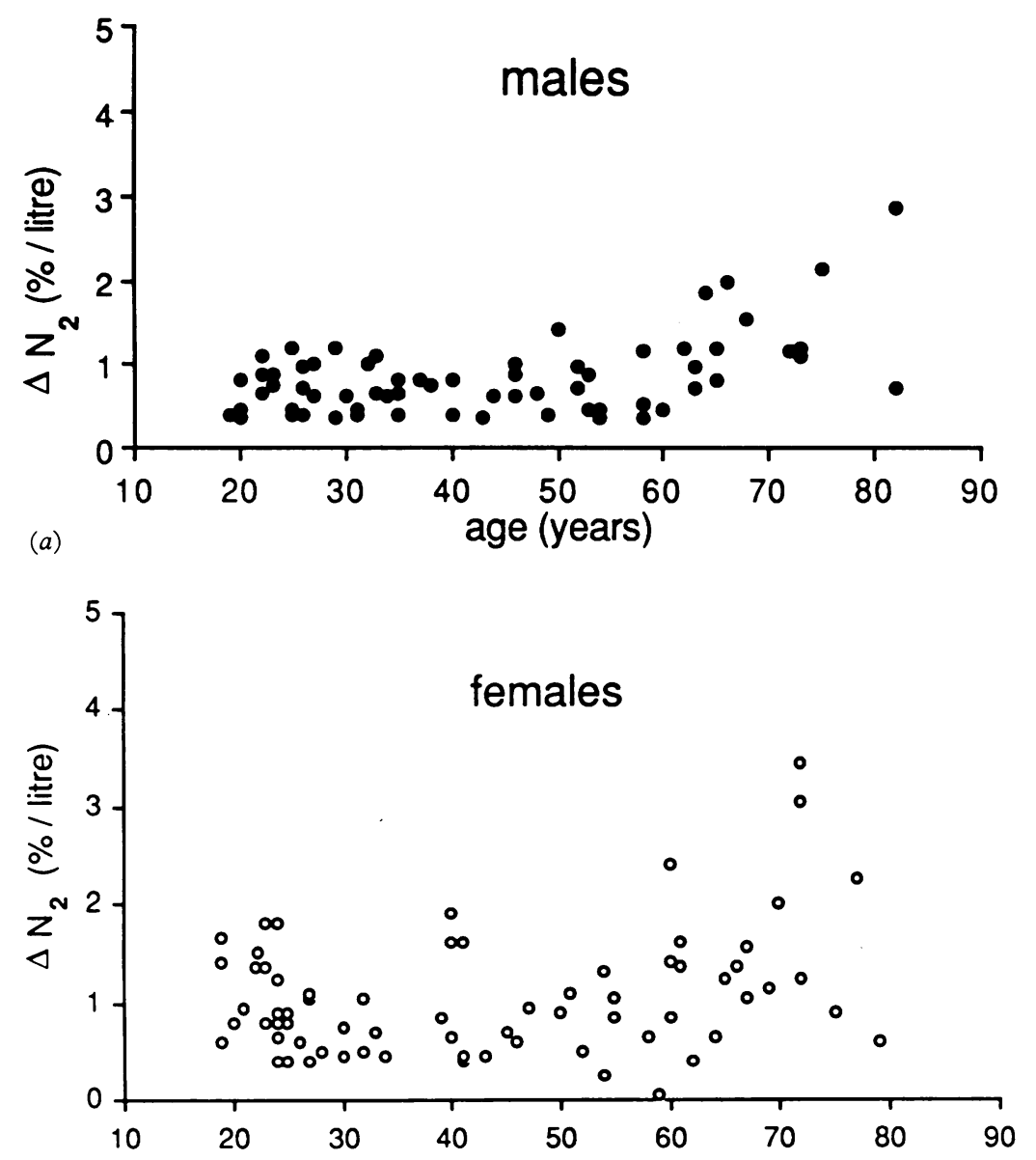

(b)

\section{age (years)}

Figure 2 Scattergrams of slope of phase III of nitrogen washout against age for (a) men and (b) women, illustrating the increased scatter of values in older subjects. Prediction equations, based on linear regression, for the full age range are given in table 3. For subjects of both sexes under 60 years narrower normal ranges are obtained by using mean and $S D$ (see text).

improve either the correlation coefficient or the standard deviation from the predicted mean. Predicted values are therefore expressed in the simpler untransformed manner used for all other lung function variables. An alternative approach $^{31}$ has been to divide the data according to the point of transformation from homoscedascity to heteroscedascity, which is age related, and to provide normal ranges up to this age (60 years in both sexes). This gives narrower normal ranges for the under $60 \mathrm{~s}$ (derived simply from the mean and SD) and may have more value for detecting early abnormalities in these age groups. Results calculated for the slope of phase III in this way are:

Men (mean 0.686\% (SD 0.285)/1): upper limit of normal (mean + 1.645 SD) $1.155 \% / 1$

Women (mean $1.039 \%$ (SD 0.616)/1): upper limit of normal $2.052 \% / 1$.

The prediction equations for closing volume and closing capacity in table 3 exclude subjects who did not show a phase IV on the nitrogen washout (closing volume $0 \%$ ). As this might create a falsely high normal range, we give alternative prediction equations that include subjects with zero values:

Men $\mathrm{CV}(\%)=0.79 \times$ age $($ years $)+0.576$

Women $\mathrm{CV}(\%)=0.153 \times$ age $($ years $)+4.741$.

\section{Discussion}

This study presents the lung function data and prediction equations derived from 179 healthy, non-smoking, white men and women who have lived all or most of their lives in an urban environment. The subjects represent a wide range of heights and ages and were drawn from various occupational and social classes. The prediction equations produced from these data provide normal values and ranges for spirometric variables, static lung volumes, transfer factor, and results of small airway tests. Such a comprehensive range of values has not previously been available for both sexes from one population group.

We have used age, height, and weight as predictors of lung function values because we found that they contribute independently to the prediction equations and comparison with existing reference values is facilitated. Multiple and exponential mathematical transformations of variables have not been shown to improve the coefficients of correlation between predicted and measured values of equations consistently ${ }^{11143233}$ and they add to the complexity of the calculations. The correlation coefficients derived from our data are similar to those from accepted reference studies with the exception of PEF equations, which have higher values than existing data.

The prediction equations for $\mathrm{FEV}_{1}$ and FVC differ from those from earlier studies ${ }^{2} 71822323435$ in that they produce higher values for a given age and height for both sexes. An example is shown in figure 3 . There are several possible reasons. Firstly, the selection of normal subjects for this study was rigorous and excluded current cigarette smokers, and exsmokers, who were often included in previous studies. In several studies a statistical difference between non-smokers and symptomless smokers or ex-smokers has been found. ${ }^{53637}$ Combining results from smokers and nonsmokers is likely to produce a lower mean value than that obtained for non-smokers alone. Secondly, prediction equations produced 20 or 30 years ago may reflect population characteristics not found in the contemporary population. Such an observation has been noted for spirometric variables ${ }^{24}$ and may account for the discrepancies between longitudinal and cross sectional studies. Thirdly, the data may be influenced by the choice of value, from the several produced by the measurements, for each lung function variable. Many previous studies have averaged the two best values for any variable or have taken $\mathrm{FEV}_{1}$ and FVC readings from the same manoeuvre. The current guidelines of the American Thoracic Society ${ }^{23}$ and the European Community for Coal and Steel working parties ${ }^{22}$ recommend that the single best values be taken independently from at least three technically acceptable maximum efforts. These standards may yield slightly higher results than those used in some earlier tests.

Although the spirometric values presented are higher than those in many earlier series they show substantial concordance with those of the three most recently published series from 
Figure 3 Examples of comparisons of predicted values from the present study and some previous studies. Graph shows forced expiratory volume in one second $\left(F E V_{1}\right)$ in men against height and age. This study; $\square$ Cotes et al $^{2} ; \bigcirc$ Morris et al ${ }^{18}$ $\triangle$ European Community for Coal and Steel working party ${ }^{22} ; \times$ Kory et al. ${ }^{32}$

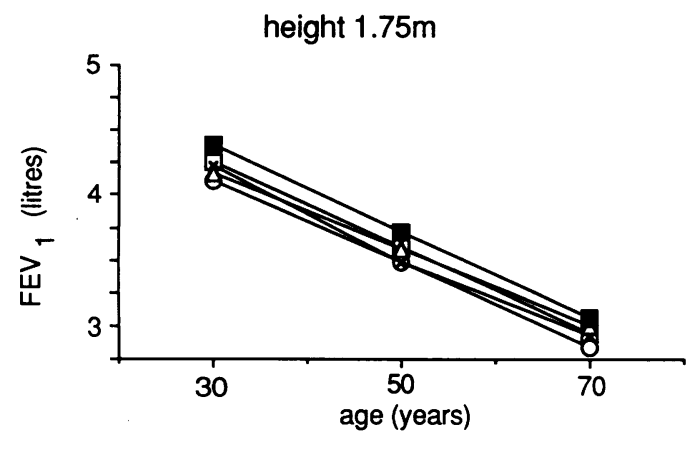

Europe and North America. ${ }^{12-14}$ These studies also excluded cigarette smokers and followed technical guidelines similar to those used in our study. The general agreement between contemporary studies and disagreement with earlier series suggests that selection criteria and newer techniques have produced reference values that should supersede those in current use. Peak expiratory flow values derived from our data predict higher values for younger subjects of both sexes but show a decline with increasing age towards levels similar to those seen in earlier studies.

At higher flows the variability of the pneumotachograph was greater than that of the dry rolling seal spirometer, and this may have contributed to some of the higher values. Any such effect could only be minor, however, because on average the spirometer gave marginally higher flow values than the pneumotachograph (appendix tables A and B).

Our prediction equations for static lung volumes in women produce values very simiar to those of other series. ${ }^{5738}$ The corresponding values in men, however, differ from those of previous studies, which have included cigarette smokers. The range of TLC values are similar to those obtained in most series ${ }^{22} 3940$ but our predicted values for VC in men are larger and those for RV are smaller. ${ }^{33}{ }^{38-40}$ As a result the $\mathrm{RV} / \mathrm{TLC}$ ratio also falls. The difference in $\mathrm{RV}$ is as much as $20 \%$ in younger, shorter subjects and falls towards parity in the tall and the elderly. An increase in RV is now recognised as an early feature of smoking related lung disease $^{41}$ and this may have influenced the results of previous studies in men, where smoking was more prevalent than among women classified as normal. The exclusion of smokers may account for our findings.

Prediction equations for carbon monoxide transfer factor yield values similar to those of other series for men, but are at the lower end of the range for women.

Normal values for the small airways tests of $\mathrm{FEF}_{50}$, closing capacity, closing volume, and $\Delta \mathrm{N}_{2} \% / 1$ have also been produced. The $\mathrm{FEF}_{50}$ is considered by many to be a sensitive test of small airways obstruction ${ }^{42-45}$ but its clinical use has been hampered by widely differing normal values from different series ${ }^{22}$ and wide ranges about the mean values. ${ }^{56}$ Our values are similar in magnitude to those obtained previously, though the values for women have a smaller variation about the mean, which should improve their usefulness. $R$ values as low as $0.47\left(R^{2}=0.22\right)$, however, exist for $\mathrm{FEF}_{50}$ (table 3), which implies that only $22 \%$ of the variance of the observed values is accounted for by age. Similar low $\mathrm{R}$ values have been found by previous workers, ${ }^{3146}$ and they imply that other independent variables, not yet identified, should be included in the prediction equations.

The correlation coefficients for the $\Delta \mathrm{N}_{2} \% / 1$ are even lower, only age having a significant, though weak, effect on the value. This prediction is further complicated by a strongly positive skew in the distribution of measured values, due to wider scatter in older subjects (fig 2). Such heteroscedascity reduces the value of regression analysis, which provides normal ranges that are too wide at the lower values and too narrow at higher values. This reduces the sensitivity of the test (which has recently been shown to help to predict the decline of $\mathrm{FEV}_{1}$ in cigarette smokers $\left.{ }^{47}\right)$. An alternative approach (see "Results") is to provide a fixed normal range based on mean values and standard deviations up to the age of 60 , as up to this age $\Delta \mathrm{N}_{2} \% / \mathrm{l}$ is effectively independent of age (fig 2).

Values of closing volume and closing capacity are similar to those found in previous studies but are derived from a larger British series than has previously been available. For reasons given below, we have chosen a one sided $95 \%$ normal range for these values and the $\Delta \mathrm{N}_{2} \% / 1$.

The ability of predicted values to discriminate between normal and abnormal function depends on how normal ranges for each variable are defined. This subject has been extensively debated ${ }^{48-50}$ and the use of percentage predicted ranges has been universally condemned. They nevertheless remain in use because of ease of calculation and familiarity. The homoscedastic distribution of almost all normal values makes the use of the standard deviation from the mean a much more appropriate expression of the normal range. For variables that may be abnormal in either direction-for example, TLC-a two sided 95\% range ( $\pm 1.96 \mathrm{SD})$ should be used, whereas for those variables where only a low value (for example, $\mathrm{FEV}_{1}$ ) or a high value (for example, $\Delta \mathrm{N}_{2} \% / \mathrm{l}$ ) is of significance, a one sided $95 \%$ range (either - or $+1.645 \mathrm{SD}$ ) is appropriate. This approach has a sound observational and statistical basis and provides a single normal range that can be applied to the predicted value for any individual.

The data presented are derived from healthy non-smoking subjects and provide predicted normal values and ranges for such a population group. These values are intended to be used in a clinical setting to assist in early diagnosis and assessment of functional impairment of lung disease. The exclusion of cigarette smokers and individuals with respiratory symptoms improves the sensitivity of applying derived normal values to patients with suspected respiratory disease. 


\section{Appendix}

Table A Comparison of means, standard deviations $(S D)$, and coefficients of variation (CV\%) for lung function variables tested in 15 normal subjects on $(a)$ both the Vertek/PK Morgan (PKM) combination and the Gould lung function computer (Gould 1) and (b) the Gould on two separate occasions (Gould 1, Gould 2)

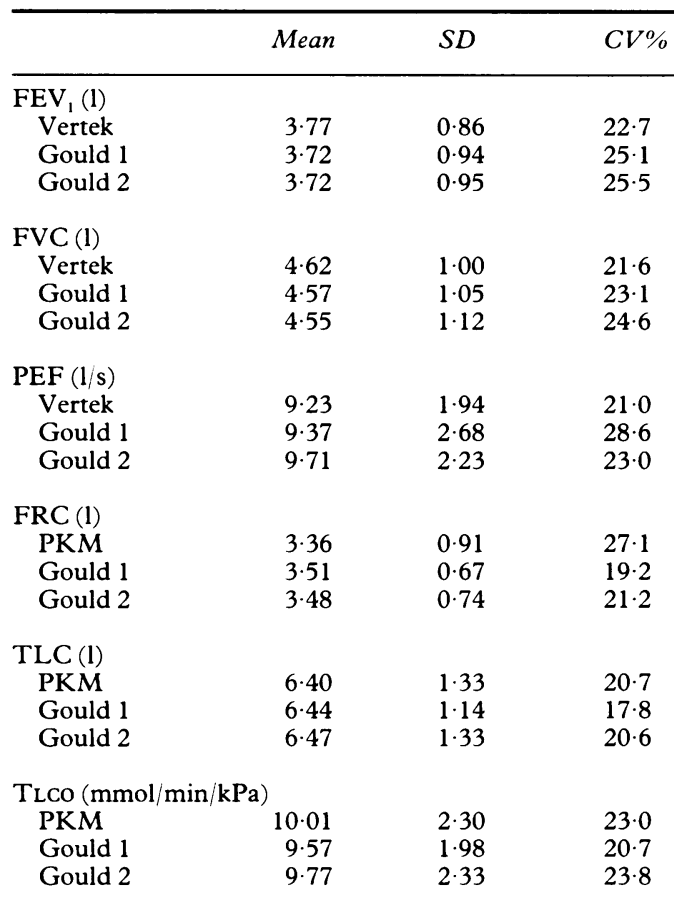

$\mathrm{FEV}_{1}$ - forced expiratory volume in one second; FVC-forced vital capacity; PEF-peak expiratory flow; FRC - functional residual capacity; TLC-total lung capacity; TLCO-carbon monoxide transfer factor.
1 Leiner GC, Abramowitz S, Small MJ, Stenby VB, Lewis WA. Expiratory peak flow rate. Am Rev Respir Dis 1963;88:644-51.

2 Cotes JE, Rossiter CE, Higgins ITT, Gilson JC. Average normal values for the forced expiratory volume in white caucasian males. BMJ 1966; i:1016-9.

3 Milne JS, Williamson J. Respiratory function tests in older people. Clin Sci 1972;42:371-81.

4 Schmidt C Du W, Dickman ML, Gardner RM, Brough FK Spirometric standards for healthy elderly men and women. Am Rev Respir Dis 1973;108:933-9.

5 Black LF, Offord K, Hyatt RE. Variability in the maximal expiratory flow volume curve in asymptomatic smokers and non-smokers. Am Rev Respir Dis 1974;110:282-92.

6 Schoenberg JB, Beck GJ, Bouhuys A. Growth and decay of pulmonary function in healthy blacks and whites. Respir Physiol 1978;33:367-93.

7 Hall AM, Heywood C, Cotes JE. Lung function in healthy British women. Thorax 1979;34:359-65.

8 Motley HL. The use of pulmonary function tests for disability approval: including evaluation standards in chronic pulmonary disease. Dis Chest 1953;24:378-89.

9 Cherniack RM, Raber MB. Normal values for ventilatory function using an automated wedge spirometer. Am Rev Respir Dis 1972;106:38-46.

10 Ferris BG, Anderson DO, Zickmantel R. Prediction values for screening tests of pulmonary function. Am Rev Respir Dis 1965;91:252-61.

11 Dockery DW, Ware JH, Ferris BG Jr, et al. Distribution of forced expiratory volume in one second and forced vital capacity in healthy white, adult never-smokers in six U.S. cities. Am Rev Respir Dis 1985;131:511-20.

12 Miller A, Thornton JC, Warshaw R, Bernstein J, Selikoff IJ Teirstein AS. Mean and instantaneous expiratory flows, FVC and FEV, prediction equations from a probability sample of Michigan, a large industrial state. Clin Respir sample of Michigan, a larg
Physiol 1986;22:589-97.

13 Paoletti P, Pistelli G, Fazzi P, et al. Reference values for vital capacity and flow-volume curves from a general population study. Bull Eur Physiopathol Respir 1986;22:451-9.

14 Roca J, Sanchis J, Agusti-Vidal A, et al. Spirometric reference values from a Mediterranean population. Bull Eur Physiopathol Respir 1986;22:217-24.

15 Ayub M, Zaidi SH, Burki NK. Spirometry and flow-volume curves in healthy normal Pakistanis. Br J Dis Chest 1987 81:35-44.

16 Withers RT, Bourdon PC, Crockett A. Lung volume

Table B Analysis of results of paired tests: means, standard deviations ( $S D$ ), $t$ and $p$ values, correlation coefficients $(r)$, and coefficients of variation (CV\%) for PKM/Vertek-Gould 1 ; PKM/Vertek-Gould 2, and Gould 1 -Gould 2

\begin{tabular}{|c|c|c|c|c|c|c|}
\hline Pairs & Mean & $S D$ & $t$ & $p$ & $r$ & $C V \%$ * \\
\hline \multicolumn{7}{|l|}{$\mathrm{FEV}_{1}(\mathrm{l})$} \\
\hline Vertek-Gould 1 & 0.05 & $0 \cdot 21$ & 0.93 & $0 \cdot 37$ & 0.98 & $5 \cdot 6$ \\
\hline Vertek-Gould 2 & 0.05 & $0 \cdot 21$ & 0.98 & 0.34 & 0.98 & $5 \cdot 5$ \\
\hline Gould 1-Gould 2 & 0.00 & $0 \cdot 12$ & 0.04 & 0.97 & 0.99 & $3 \cdot 2$ \\
\hline \multicolumn{7}{|l|}{ FVC (1) } \\
\hline Vertek-Gould 1 & 0.05 & $0 \cdot 26$ & $0 \cdot 76$ & 0.46 & 0.97 & $5 \cdot 7$ \\
\hline Vertek-Gould 2 & 0.07 & $0 \cdot 32$ & 0.89 & 0.39 & 0.96 & $6 \cdot 9$ \\
\hline Gould 1-Gould 2 & 0.02 & $0 \cdot 15$ & 0.56 & 0.58 & 0.99 & $3 \cdot 3$ \\
\hline \multicolumn{7}{|l|}{$\operatorname{PEF}(1 / \mathrm{s})$} \\
\hline Vertek-Gould 1 & $-0 \cdot 14$ & $1 \cdot 58$ & -0.34 & $0 \cdot 74$ & $0 \cdot 81$ & $17 \cdot 0$ \\
\hline Vertek-Gould 2 & -0.48 & 0.92 & $-2 \cdot 04$ & 0.06 & 0.91 & 9.9 \\
\hline Gould 1-Gould 2 & -0.35 & $1 \cdot 09$ & $-1 \cdot 23$ & $0 \cdot 24$ & 0.92 & $11 \cdot 4$ \\
\hline \multicolumn{7}{|l|}{ FRC (1) } \\
\hline PKM-Gould 1 & $-0 \cdot 15$ & 0.53 & $-1 \cdot 12$ & $0 \cdot 28$ & 0.82 & $15 \cdot 3$ \\
\hline PKM-Gould 2 & $-0 \cdot 12$ & 0.33 & $-1 \cdot 35$ & $0 \cdot 20$ & 0.94 & $9 \cdot 8$ \\
\hline Gould 1-Gould 2 & 0.04 & $0 \cdot 36$ & $0 \cdot 38$ & $0 \cdot 71$ & $0 \cdot 88$ & $10 \cdot 3$ \\
\hline \multicolumn{7}{|l|}{ TLC (1) } \\
\hline PKM-Gould 1 & -0.04 & 0.56 & $-0 \cdot 27$ & $0 \cdot 79$ & 0.91 & $8 \cdot 6$ \\
\hline PKM-Gould 2 & -0.07 & $0 \cdot 31$ & -0.86 & 0.40 & 0.97 & $4 \cdot 8$ \\
\hline Gould 1-Gould 2 & -0.03 & $0 \cdot 45$ & $-0 \cdot 25$ & $0 \cdot 81$ & 0.95 & $6 \cdot 9$ \\
\hline \multicolumn{7}{|l|}{$\mathrm{TlCO}_{\mathrm{LCO}}(\mathrm{mmol} / \mathrm{min} / \mathrm{kPa})$} \\
\hline PKM-Gould 1 & $0 \cdot 44$ & $0 \cdot 87$ & $1 \cdot 88$ & $0 \cdot 82$ & 0.93 & $6 \cdot 5$ \\
\hline PKM-Gould 2 & $0 \cdot 24$ & 0.64 & 1.41 & $0 \cdot 18$ & 0.96 & $6 \cdot 5$ \\
\hline Gould 1-Gould 2 & $-0 \cdot 20$ & 0.59 & $-1 \cdot 24$ & $0 \cdot 24$ & 0.98 & $6 \cdot 1$ \\
\hline
\end{tabular}

${ }^{\star} \mathrm{CV} \%=(\mathrm{SD}$ of differences mean value $)$ of the two systems compared.

Abbreviations as in table A. 
standards for healthy lifetime non-smokers. Chest 1988; 93:91-7.

17 Nunn AJ, Gregg I. New regression equations for predicting peak respiratory flow in adults. $B M J 1989 ; 298: 1068-70$.

18 Morris JF, Koski A, Johnson LC. Spirometric standards for healthy non-smoking adults. Am Rev Respir Dis 1971; 103:57-67.

19 Crapo RO, Morris AH, Gardner RM. Reference spirometric values using techniques and equipment that meet ATS recommendations. Am Rev Respir Dis 1981;123:659-64.

20 Burr ML, Phillips KM, Hurst DN. Lung function in the elderly. Thorax 1985;40:54-9.

21 Fowler RW, Pluck RA, Hetzel MR. Maximal expiratory flow volume curves in Londoners aged 60 years and over. Thorax 1987;42:173-82.

22 Quanjer $\mathrm{Ph} \mathrm{H}$, ed. Standardised lung function testing report of the European Community for Coal and Steel working party. Bull Eur Physiopathol Respir 1983;19:suppl 5.

23 American Thoracic Society. Standardisation of Spirometry. Am Rev Respir Dis 1987;136:1285-98.

24 Glindmeyer HW, Diem JE, Jones RN, Weill H. Non comparability of longitudinally and cross sectionally determined annual change in spirometry. Am Rev Respir Dis 1982;125:544-8.

25 Knudson RJ, Lebowitz MD, Holberg CJ, Burrows B Changes in the normal maximal expiratory flow-volume curve with growth and aging. Am Rev Respir Dis 1983; 127:725-34

26 Burrows B, Lebowitz MD, Camilli AE, Knudson RJ. Longitudinal changes in forced expiratory volume in one second in adults. Am Rev Respir Dis 1986;133:974-80.

27 Tager IB, Segal MR, Speizer FE, Weiss ST. The natural history of forced expiratory volumes. Am Rev Respir Dis 1988; 138:837-49.

28 Ferris BG. Epidemiology standardisation project. Am Rev Respir Dis 1978;118:55-88.

29 Ogilvie CM, Forster RE, Blakemore WS, et al. A standardised breath holding technique for the clinical measurement of the diffusing capacity of the lung for measurement of the diffusing capacity of the

30 Buist AS, Ross BB. Predicted values for closing volumes using a modified single breath nitrogen test. Am Rev Respir Dis 1973;107:744-52

31 Buist AS, Ross BB. Quantitative analysis of the alveolar plateau in the early diagnosis of early airways obstruction. Am Rev Respir Dis 1973;108:1078-87.

32 Berglund E, Birath G, Bjure J, et al. Spirometric studies in normal subjects. I. Forced expirogram in subjects between 7 and 70 years of age. Acta Med Scand 1963;173:185-92.

33 Knudson RJ, Slatin RC, Lebowitz MD, Burrows B. The maximal expiratory flow volume curve Normal standards, variability and effects of age. Am Rev Respir Dis 1976;
113:587-600.

34 Kory RC Callahan R, Boren HG, Syner JC. The Veterans Administration-Army cooperative study of pulmonary function: I. Clinical spirometry in normal men. Am J Med 1961;30:243-58.

35 Boren HG, Kory RC, Syner JC. The Veterans Administration-Army cooperative study of pulmonary function. II. The lung volume and its subdivisions in normal man. Am J Med 1966;41:96-114.

36 Miller A, Thornton JC, Warshaw R, et al. Single breath diffusing capacity in a representative sample of the population of Michigan, a large industrial state. Am Rev Respir Dis 1983;127:270-7.

37 Gregg I, Nunn AJ. Peak expiratory flow in symptomless elderly smokers and ex-smokers. $B M J 1989 ; 298: 1071-2$.

38 Goldman HI, Becklake MR. Respiratory function tests. Normal values at median altitudes and the prediction of normal results. Am Rev Tuberc 1959;79:457-67.

39 Needham CD, Rogan MC, McDonald I. Normal standards for lung volumes, intrapulmonary gas mixing, and maximum breathing capacity. Thorax 1954;9:313-25.

40 Grimby G, Soderholm B. Spirometric studies in normal subjects. III. Static lung volumes and maximum voluntary ventilation in adults with a note on physical fitness. Acta Med Scand 1963;173:199-206.

41 Blackburn H, Brozek J, Taylor HL. Lung volume in smokers and non-smokers. Ann Intern Med 1959;51: 68-77.

$42 \mathrm{McFadden}$ ER, Linden DA. A reduction in maximum midexpiratory flow rate. Am J Med 1972;52:725-37.

43 Berend N, Woolcock AJ, Marlin GE. Correlation between the function and structure of the lung in smokers. Am Rev Respir Dis 1979;119:695-705.

44 Adams L, Lonsdale D, Robinson M, Rawbone R, Guz A. Respiratory impairment induced by smoking in children in secondary schools. BMJ 1984;288:891-5.

45 Wright JL, Lawson LM, Pare PD, et al. The detection of small airways disease. Am Rev Respir Dis 1984;129: 989-94.

46 Bass $\mathrm{H}$. The flow volume loop: normal standards and abnormalities in chronic obstructive pulmonary disease. Chest 1973;63:171-6.

47 Oloffson J, Bake B, Svardsudd K, Skoogh BE. The single breath $\mathrm{N}_{2}$ test predicts the rate of decline in $\mathrm{FEV}_{1}$. Eur $\mathrm{J}$ Respir Dis 1986;69:46-56.

48 Sobol BJ, Weinheimer B. Assessment of ventilatory abnormality in the asymptomatic subject: an exercise in futility. Thorax 1966;21:445-9.

49 Sobol BJ. The early detection of airway obstruction: another perspective. Am J Med 1976;60:619-24.

50 Miller MR, Pincock AC. Predicted values: how should we use them? Thorax 1988;43:265-7. 